YAEL BEN-MOSHE

Bucerius Institute for Research of German History and Society Haifa Center for German and European Studies, University of Haifa

TOBIAS EBBRECHT-HARTMANN

DAAD Center for German Studies Department of Communication \& Journalism The Hebrew University of Jerusalem
Images vol. XXV/no. 34

Poznań 2019

ISSN 1731-450X

\title{
Terror films: The socio-cultural reconstruction of trauma in contemporary Israeli cinema*
}

\begin{abstract}
Aвstract. Ben-Moshe Yael, Ebbrecht-Hartmann Tobias, Terror films: The socio-cultural reconstruction of trauma in contemporary Israeli cinema. "Images" vol. XXV, no. 34. Poznań 2019. Adam Mickiewicz University Press. Pp. 69-86. ISSN 1731-450X. DOI 10.14746/i.2019.34.05.

The public discourse in Israel regarding events such as the Holocaust, war, or terror attacks mostly failed to embrace the trauma caused by such events, and to integrate their effects in the collective memory. According to trauma theoreticians, the location of trauma in the discourse is related to the character of trauma as a non-narratable memory, since personal trauma exist in the void, thus marking a missing memory. This paper explores the notion of trauma in contemporary Israeli cinema as it was reconstructed during and after the Second Intifada (2000-2008). The paper focuses on feature films reflecting on experiences of terrorist violence, among them Avanim (2004), Distortion (2004), Frozen Days (2006), The Bubble (2006), 7 Minutes in Heaven (2009). These films embrace parallel elements structuring a worldview, in the private as well as the collective sphere, thus shaping the surroundings as a mirror of the self and the subjective traumatic experience as a reflection of a complex social reality. A particular focus of our analysis will also be on aesthetic strategies that cinematically express rupture and distortion of terrorist violence and trauma, especially moments of suddenness and disruption in contrast to duration and circular repetition, elements of a specific temporality of trauma that also shaped the narration and style of recent Israeli war films, such as Waltz with Bashir (2008) or Beaufort (2007).
\end{abstract}

KEYwORDS: trauma, terror, terrorism, Israeli cinema, war, Second Intifada

The experience of terror and terrorism has been an essential part of Israeli public and private life ever since, and even before, the establishment of the Jewish state.[1] After the heyday of Palestinian terrorism during the 1970s, mostly performed in an international arena by groups such as the Black September Organization or the Popular Front for the Liberation of Palestine, the ongoing conflict between Palestinians and Israelis is significantly shaped today as asymmetrical warfare, dominated by fundamentalist militant groups such as Hamas in Gaza

* The authors thank Uta Larkey and Raya Morag for instrumental comments on previous versions of this article.

[1] Before the establishment of the state, the conflict with the Arabs of Palestine was characterised by ter- rorism, like the murder of Y.H. Brenner in Jaffa, the massacre in Hebron, the attacks on Jewish civilians in 1936-1939, the attack on the medical convoy after the events in Dir Yasin. 
or Hezbollah in Lebanon. The period in-between was characterised by a mortal series of suicide attacks in the Israeli heartland that dramatically affected the Israeli public, as well as personal perceptions of the conflict within the Israeli population. Although the Second Intifada can be considered an important turning point in the history of the Israeli-Palestinian conflict and shaped political consciousness to this day, Israeli cultural products rarely dealt explicitly with these experiences with terrorism, especially the occurrence of a 'new' form of collective trauma. Compared with the dominant role of wartime memories and Holocaust memory in Israeli visual culture, film directors avoided direct references to the impact of terrorism and trauma in their works.

This paper focuses on the existing direct and indirect representations of terrorism and trauma in Israeli feature films produced during and after the Second Intifada (2000-2009). We argue that during and after the Second Intifada, filmmakers chose to concentrate on personal experiences and avoided narratives that could serve the codification of memory. Accordingly, Israeli filmmakers, on the one hand, began dealing with the traumatic present; however, on the other hand, they detached this trauma from its cultural or historical context. By doing so, they nevertheless reconstructed the act of terrorism in correspondence with the socio-psychological limitations of recapturing and re-experiencing such events. Eventually, these films proposed to simulate representations without upsetting the audience or arousing public condemnation.

In the following, we intend to show how these films succeeded to convey, but also to trigger, a sense of what psychologists define as 'trauma.' This affective dimension of trauma is intensified by the use of specific cinematic aesthetics that allude to the disruptive character of a terror attack in order to create a sensory overloaded experience.[2] Furthermore, we intend to re-contextualize traumatic events on the basis of imaginary manifestations.

We explore this interplay of terrorism and trauma through an analysis of mostly Israeli independent and low-budget films produced between 2004 and 2012: Avanim (2004), Distortion (2004), Frozen Days (Yamim Kfuim, 2006), The Bubble (Ha-Buah, 2006), and 7 Minutes in Heaven (Sheva Dakot be Gan Eden, 2009). In addition, we propose that in contrast to these films, Israeli mainstream cinema mainly dealt with the post-Second Intifada trauma through the war film genre by reconstructing different events from the past. Indirectly referencing disruptive and dissonant terror, the contemporary experience of suicide terrorism shaped the aesthetics and perception of these films. In conclusion, we will discuss this implicit depiction of terror and trauma in Israeli cinema by briefly analysing the films Beaufort (2007) and Waltz with Bashir (Vals im Bashir, 2008).

[2] "By staging its non-representability, film overcomes and challenges the vision of 'trauma' as non-representable and turns it into an artistic creation." The Horror of Trauma in Cinema: Violence Void Visualization, Newcastle upon Tyne, eds M. Elm, K. Kabalek, J.B. Köhne, Cambridge 2014, p. 11. 
The International Dictionary of Psychoanalysis defines trauma as Trauma and memory "an event of such violence and suddenness that it occasions an inflow of excitation sufficiently strong to defeat normally successful defence mechanisms." [3] In other words, trauma is an event in which sensory overload, stimulated by the event, prevents an immediate psychological processing of the occurrence. Schauer, Neuner, and Elbert propose a similar definition, but also include the psychological impact of the event.[4] In clinical terms, 'trauma' points to the physical damage caused by an event. However, various theoreticians and psychologists of trauma, among them Lewis, Kelly, and Allen,[5] Cato,[6] and Pearlman and Saakvitne, assert that emotional and mental stress also trigger psychological trauma as a "unique individual experience of an event or of enduring conditions in which the individual's ability to integrate his or her emotional experience is overwhelmed, or the individual experiences a threat to life, bodily integrity, or sanity".[7] Thus, there are many different causes for psychological trauma. Trauma can be caused by powerful, random incidents, such as a natural disaster, a terror attack, an accident, or the death of a loved one. It can also result from enduring or repetitive experiences, such as war, physical abuse or violence, or severe neglect.[8] All causes of trauma "commonly include abuse of power, betrayals of trust, entrapment, helplessness, pain, confusion, and/or loss." [9]

A lasting response to a traumatic event is recognised by the American Psychiatric Association as a mental disorder, specifically post-traumatic stress disorder (PTSD). The American Psychiatric Association lists the symptoms of PTSD as follows: Intrusive thoughts, such as distressing dreams or flashbacks of the traumatic event; avoiding reminders of the traumatic event, negative thoughts and feelings, ongoing fear, anger, guilt; feeling detached or estranged from others, and having angry outbursts, behaving recklessly or in a self-destructive way.[10]

Historian Ruth Leys asserts that:

Post-traumatic stress disorder is fundamentally a disorder of memory. The idea is that, owing to the emotions of terror and surprise caused by certain events, the mind is split or disassociated: it is unable to register the wound

[3] International Dictionary of Pschoanalysis, ed. A. De Mijolla, London 2002, pp. 1800-1802.

[4] "Psychological 'Trauma' is the experience and psychological impact of events that are life threatening or include a danger of injury so severe that the person is horrified, feels helpless, and experiences a psychophysiological alarm response during and shortly following the experience." M. Schauer, F. Neuner, and T. Elbert, Narrative Exposure Therapy: A Short-Term Intervention for Traumatic Stress Disorders after War, Terror, or Torture, Göttingen \& Cambridge 2005, p. 5. [5] L. Lewis, K. Kelly, J.G. Allen, Restoring Hope and Trust. An Illustrated Guide to Mastering Trauma, Baltimore 2004, p. 12.
[6] D. Cato, Saving the Leader Within: The Impact of Childhood Trauma on Leadership, Bloomington 2011, p. 167.

[7] L.A. Pearlman, K.W. Saakvitne, Trauma and the Therapist: Countertransference and Vicarious Traumatization in Psychotherapy with Incest Survivors, New York 1995.

[8] L. Lewis, K. Kelly, J.G. Allen, op.cit., p. 7.

[9] D. Cato, op.cit., p. 167.

[10] American Psychiatric Association, Diagnostic and Statistical Manual of Mental Disorders, 5 th ed., Washington, DC 2013, <https://www.psychiatry.org/ patients-families/ptsd/what-is-ptsd $>$ [accessed: July $12,2017]$. 
to the psyche because the ordinary mechanisms of awareness and cognition are destroyed. As a result, the victim is unable to recollect and integrate the hurtful experience in normal consciousness; instead, [the person] is haunted or possessed by intrusive traumatic events. The experience of the trauma, fixed or frozen in time, refuses to be represented as past, but is perpetually re-experienced in a painful, dissociated, traumatic present.[11]

Kansteiner and Weilnböck point out that trauma theories thus engage mostly with the unarticulated or unrecalled components that signify trauma and are less interested in the conscious, active memories of the event, which are intertwined with daily life and are, in fact, no less important for the later effects of the event.[12] In other words, most trauma theories focus on the missing and suppressed parts of memory, while the unavoidably present memories attract less attention, since they are "in process." And yet, these recollections live and are evoked over the course of time and are integral to normal experiences.

Theoretical experiences

Trauma and terrorism
Exposure to an event can occur on different levels: "Exposure to violence can include witnessing violence, being directly victimised by violence, and possessing knowledge of violence." [13] Since one of terrorism's aims is to advertise itself, and the psychological effects are no less significant than the physical damage, the circle of exposure to terrorism has been dramatically widened in the Western world since the beginning of the millennium, whether through direct experiences or through representations in the media.

Elsaesser asserts that "when speaking of terror and trauma, it is often as if actual violence has become indistinguishable from symbolic, somatic, and semantic violence." [14] Exposure based on possessing knowledge of violence is indeed indistinguishable from symbolic or semantic violence. But for witnesses of violence or its immediate victims, media representations can help in reshaping personal memories of traumatic events. Thus, media representations have a strong impact on the perception of terrorist violence, although they have to be distinguished clearly from the victim's or witness' own memories of the events.

It is vital to designate and particularise the notion of traumatic memory in its immediate relations to terrorism. Drawing on Derrida, Elsaesser notes that:
[11] R. Leys, Trauma: A Genealogy, London \& Chicago 1990, p. 2.

[12] W. Kansteiner, H. Weilnböck, Against the Concept of Cultural Trauma, Berlin 2008, p. 233.

[13] "Exposure to violence has been linked consistently to a range of psychological problems in children and adolescents including traumatic stress, anxiety, depression, substance use, aggressive and antisocial behaviour problems, and academic difficulties."

P. Boxer and E. Sloan-Power, Coping with Violence:
A Comprehensive Framework and Implications for Understanding Resilience, "Trauma, Violence and Abuse" 2013, vol. 14, no. 3, p. 209; see also L.J. Jasinski, Trauma and Violence Research, "Journal of Interpersonal Violence" 2005, pp. 412-417.

[14] T. Elsaesser, The Trauma of Terrorism: Violence of the Past in the Present, "Trauma Interdisciplinar" 2015, vol. 6, no. 1, <http://editorarevistas.mackenzie.br/ index.php/tint/article/viewFile/7947/5263> [accessed: May 21, 2018]. 
The terrorists' act is a product of what it rejects, a mirror image of its target. [...] The prognosis is sombre: a product of the violence that seeks to suppress it, terrorism has created a trauma that cannot be relieved by mourning, because the heart of trauma is not the past event, but fear of a future event whose catastrophic nature can only be guessed. [...] The circle is almost unbreakable: terrorism and what it is against are locked in a reciprocal game of destruction, where causes may no longer be distinguished from consequences.[15]

The apprehension caused by the possibility that this kind of event could be repeated, the fear of the unknown, the future, is embedded in the self and changes the dynamics between time and memory. Past events are stretched into the future and are therefore influential in the orientation of trauma.

Morag argues that the Second Intifada, with its frequent suicide bombings between October 2000 and November 2004, created a chronic psychosocial trauma in Israel, while filmmakers and the public discourse mostly excluded the subject.[16] She claims that by avoiding a direct representation of the act of terror, films created a reality of anti-memory, a reality devoid of trauma. On the one hand, films depicting terrorist attacks reproduce what is known from news reports: distant views, long shots and the invisibility of dead bodies.[17] On the other hand, the collective imagination of suicide attacks in Israel is primarily acoustic: "Like the traumatic event itself, signified by its reverberating boom, the sound is conceptualised only later, in its imagined post-effect." [18] Hence, the detonation and its suddenness mark always just the endpoint of an action, which eludes our perception. Correspondingly, we approach the reality of the attack only in terms of its "visual aftermath". [19] This results in a different temporal structure, which also affects the capability of memory: "pre-memory is the time of the attack, the time that 'any minute an attack can happen', on the other, it is the other time, the interval." [20] This results in a paradox temporal structure, which is characterised by uniqueness (monadic temporality) and repetition (circular temporality), or in Morag's words, is "simultaneously one-time and chronic." [21] For this reason, the terrorist attack comprises at once a multitude of events (an interval) and also marks a rupture.

[15] Ibidem, p. 41. Baudrillard takes a similar approach, likening terrorism to a virus, living in a system that nurtures it. According to Baudrillard, terrorism aims to produce consequences that are destructive, but not so destructive as to cause the total annihilation of the system. The resulting regression of the system, like trauma, is a protective mechanism against the repetition of a similar event and against the unknown. Baudrillard notes that there is "no possible distinction between the 'crime' and the crackdown. And it is this uncontrollable unleashing of reversibility that is terrorism's true victory." J. Baudrillard, op.cit., p. 31.

[16] R. Morag, Chronic Trauma, the Sound of Terror, and Current Israeli Cinema, "Framework: The Journal of Cinema and Media" 2008, vol. 49, no. 1, pp. 121-133.

[17] Ibidem, p. 121.

[18] Ibidem.

[19] Ibidem.

[20] Ibidem, p. 124.

[21] Ibidem, p. 125. 
Correspondingly, the films under review in this article offer a different approach to trauma than former depictions of disaster and conflicts causing collective trauma, such as war and genocide. Trauma is located in everyday actions, as well as in the "voids" of the drama, and thus cannot be transformed into a comprehensive narrative in order to be present. Accordingly, many of the films also do not shy away from representing the explosive attack itself. By representing the attacks and transforming terrorist violence into stylistic and narrative forms, they expose both the characters and the audience to the violence of terrorism and the trauma that follows in the various ways mentioned above.

This is further intensified by an experiential temporality based on contrasts. Israeli films weaved the subjects of terrorism and trauma during and after the Second Intifada into a realm of opposites or counterpart modes: the need to remember and the wish to forget; the private realm and public commemoration; eternity and the passing moment; life and death. Such opposites furthermore emphasise the gaps between private perception and public discourse on terrorism and trauma.

Trauma and terrorism in recent Israeli films
The plot of the film Avanim, from 2004, centres around protagonist Michal, a mother and a married woman in her mid-3os. Michal's tragedy appears outside the circle of "normality" and routine, as a hidden, illegitimate part of her life - the death of her lover, who was killed in a suicide bombing at a café where they had scheduled a date. Michal was late for their meeting, and the couple is therefore separated by death. The explosion itself, for both Michal and the viewers, is silenced, unheard. Instead, the ambulance's shrieking siren circles the confused and stunned crowed.

At home, Michal is unable to share her loss or her thoughts about her lover or herself. She tries to be reserved and act as usual in order to keep her family together. For a while, she is able to wear this mask. But with time, in an environment teeming with conflicts, between suppression and the legitimacy to grieve and surrender to emotions, 'explosions' appear and are heard over and over again in her personal life and in the relationships with the people around her.

The café bombing, as an "outer" conflict, upsets the balance she was trying to maintain and forces her to remove the fake mask she wore for a long time, until she decides to leave her husband.

Nadjari uses naturalistic colourisation as well as the integration of sounds of motion, streets and nature to capture the external environment in a realistic mode. These external voices of the living, of the collective, while enveloping the silence of Michal, do not invade her private world. In contrast, the director utilises fast camera movements and shooting with a handheld camera to reflect the restless mind and soul of Michal. In addition, parallel with long silenced scenes between numerous meaningless conversations, the close shots of body parts, of objects, and often blurry close-ups and frames support the conflicting 
and estranged environment, and the instability and the depersonalisation of the heroine and her surroundings. Nadjari uses the act of depersonalisation also against those who represent the authorities; the policemen, the medical team at the hospital or at the information desk. These are all faceless people who do not penetrate her world; in contrast to those who died and cannot be heard - her mother, her lover and the friend - they are not playing any real part in her private world. But while gravestones marking the burial place of the dead are obviously made of stone, this material - which gives the film its title, Avanim - can serve the living as well, as in the construction of homes and institutes of learning. This duality comes into full display in the construction of the center for the study of the Torah founded by her father in memory of Michal's mother. This center, built in stone, is a place for the living to commemorate and unite with the dead. The perpetuation of life or the commemoration of the dead through the establishment of an institution illustrates an official collective agenda, according to which loss and grief embed a moral and value-based meaning and are therefore legitimate. In contrast, Michal's private experience, the illegitimacy of her grief, is exemplified once again by the refusal of the medical team to provide Michal with any information, as she is not kin to the deceased.

Finally, her personal trauma and tragedy narrow the edges of her ability to negotiate with herself, and eventually she exposes the corruption concerning the funding of the Torah centre handled by her father's firm, ultimately forcing him to shut it down. While struggling with her own loss, Michal refuses to conform to and accept what she perceives and symbolises the dishonest tradition of collective commemoration. And so, Michal, distracted in her actions, thoughts, and feelings, finds herself bereft of a specific time or place to grieve her own tragedy.

Such counterpart-modes are articulated further in the film The Bubble from 2006. A "bubble" in the Israeli jargon refers often to the citizens of Tel-Aviv, or generally to people who are detached or not influenced by their surroundings, in this case, the continuous Israeli-Palestinian conflict and accompanying terror attacks. The conflict is perceived not to intrude upon or interrupt their private bohemian life in the "bubble", where all people are welcomed.

The romantic drama takes place in Tel Aviv and portrays the lives of three young flatmates. The first time a terrorist attack occurs is over halfway into the story, as an arbitrary act that takes place within routine and "normality." The first explosion is heard, but images from the terror scene are not shown on screen. News of the attack is broadcast on television in the apartment's living room - a medium in which 'reality,' not quite belonging to the "bubble," becomes Breaking News, and breaks the consistency of life in what Baudrillard defines as the hyper-realistic world. Israeli viewers now watch the familiar pictures on TV as a sub-reflection, as a sub-image in a film - the film turned to reality and reality turned into a burdened image for the frame story. 
Interrupting the constitutive concept of flow[22] in television programming, the Breaking News following a terrorist attack corresponds to the disruptive character of an attack. While terrorist violence as a perverted form of communication seeks for public resonance, television transforms it into a 'negative' media event, thereby spreading the message of fear.[23] Furthermore, the television here is represented as a cold informative box, non-negotiable and detached from the subjective feelings of the protagonists. Correspondingly, television on the one hand bears an affinity towards terrorist violence, while cinema establishes a space for manifesting trauma.[24] On the other hand, television serves as the leading medium of the domestic sphere, thereby interrelating every-day private life with the public and the political.[25]

In contrast to the worried relatives and friends who gather around, Yahli, who was injured in the attack, seems to be fine and responds amusedly to his friends' panic. Beyond reflecting an unexpected response, this scene expresses the self-consciousness of the "bubble," unable or unwilling to acknowledge the experience of violence affecting and disrupting the joy of life. In contrast, Yahli's family sits around motionless, without touching, embracing the individual passively, in silence, thus representing the individual's post-traumatic reaction vs. the collective reaction to the individual's post-traumatic experience.

The central story that motivates the plot is based on a romantic relationship between two men: Noam, a Jewish-Israeli, and Ashraf, an Arab-Palestinian. Both carry childhood traumas that have penetrated their psychological borders as a direct or indirect result of the ongoing Israeli-Arab conflict. The film employs voiceover from the diegetic present when images from the past appear in retrospect, thus placed outside of the narrative. They do not belong to the "bubble" where the story takes place and where Noam and Ashraf's relationship should have been fulfilled. The "bubble" is a 'locus' of wishful thinking that does not reflect 'reality', but exists only when an individual externalises the trauma and its causes. At the end, it all "blows up".

The film ends with the second attack, a filmic statement viewing terrorisms' repercussions as a dagger in the hearts of the living. Enraged by his sister's death by an Israeli stray bullet in the middle of a military raid, Ashraf arrives in Tel-Aviv with the intention to execute a suicidal terror attack. Wandering in the streets of Tel-Aviv, Noam calls Ashraf's mobile phone, while all of a sudden, Noam sees Ashraf through the Cafe's windows, and runs towards the other man, who holds the detonation

[22] J. Ellis, Visible Fictions: Cinema, Television, Video, London-New York 1992, p. 65.

[23] H. Nossek, 'News media' - media events: Terrorist acts as media events, "European Journal of Communication Research" 2008, vol. 33, no. 3, p. 314. However, Nossek also emphasizes that beyond the Breaking News, television also strives for establishing communicable narratives about terrorism: "In this sense, the media defuse the narrative of disruption that terrorists seek to write 'News', and rewrite the event instead in terms of the master narrative of the beleaguered society." (p. 315).

[24] T. Elsaesser, German Cinema - Terror and Trauma: Cultural Memory Since 1945, New York-London 2004, p. 35.

[25] J. Ellis, op.cit., pp. 59-6o. 
button in his hand. Whereas in the "bubble," parallel to 'reality', pain is silenced and only the signs of joy are heard, the explosion executed by Ashraf is silenced and shuffled visually between an act of death and love, between the act of completeness and separation. Substituting the explosion by a glowing light, a basic motif in mythology, transforms Ashraf and Noam into mythical beings beyond time and place who are sentenced to fulfil their love only in death. The merging of the film into TV's Breaking News, thereby converting hyperreality into an image of 'basic reality', transforms a personal affair into a national story at this point, a personal-emotional tragedy into a reflection on the socio-political miserable, a detached and cold 'reality', where terrorism turns love to hate and life to death.[26]

Although it appears as if after both attacks the narrative apparently avoids confrontation with the consequences of the event, post-trauma, is nevertheless, integral to each voiceless scene, and expressed as an unwanted guest to a joyful life. Fear and suspicions accompany the sounds of music and laughter as shy, uninvited friends in different parts of the story, intersecting tragedy with life as an inseparable link, striving to acknowledge the horror, but at the same time to celebrate life.

The repositioning of television coverage of terrorist attacks as a reflection of 'reality' within hyperreality is repeated in many Israeli films, such as Distortion, Walk on Water (2004) and Frozen Days. Television, as a medium that converts 'reality' into reflected images and interconnects the private and the public sphere, is subsequently integrated as a medium reflecting the characters' social subconscious.

Bearing a resemblance to Lubitsch's film To Be or Not to Be (1942), Distortion captures the realm of simulation between reality and hyperreality and opens with the call for "Action!". The story opens with a woman who is waiting for her blind date to show up at a café. Shortly after, Haim, a frustrated theatre director (played by the film's director with the same name) suffering from writer's block, finishes his coffee and is heading home. Minutes later, Distortion shuffles the sound of the explosion in blinding, flickering light. The camera stutters through a juxtaposition of dark and blinding frames, implying and creating a visual sensory overload through the inability to look at the screen and comprehend what we get to see until total darkness. In this manner, the film fuels a discourse about the limitations of visual comprehension, fostered by the aesthetics of suddenness and a tumbling camera that loses its physical and psychic ground; immediately afterwards, the scene of the attack is shot in tilt-up through the perspective of one of the burned victims who was thrown from the blast to the ground. Correlating with the reality it represents, Distortion, framed by the

[26] Raya Morag has offered a different reading of this film. She analyses its end as a "romanticized, self-centered gay fantasy", which does not only exclude the reality of occupation but also ignores the "nature of post-trauma of Israelis". R. Morag, Interra- cial (Homo) sexualities: post-traumatic Palestinian and Israeli cinema during the al-Aqsa Intifada (Diary of a Male Whore and The Bubble), "International Journal of Communication" 2010, vol. 4, p. 950. 
same attack, emphasizes ruptures at the surface of the (movie) image, and finally enters a repetitive loop.

Haim is deeply disturbed; his psychiatric medication supposedly helps him to live in the shadow of regularly reported terrorist attacks, but he can barely function, and it also prevents him from enjoying sexual relations with his wife. As in the other films we have mentioned, the violent threat challenges love and life by fear of separation from the body, fear of destruction, misery, and death.

The film's title is also the title of a play that Haim is directing. 'Distortion' stands for his description of the people in a society on the edge, in a psychotic state, in which paranoia and suspicion - both in reality and in the play - are described as a "flourishing business," and become a dominant motif and ground for either creation or destruction. Moreover, the characters' names in the film are the names of the actors in real life, suggesting that the film is a reflection of reality, in the same way that the play Haim is directing is a reflection of the film's narrative. His trauma, fragility and the distortions he encounters are conveyed through the performance he directs, in which everything he is unable to express and share in real life can finally be heard. The stage enables Haim for the first time to communicate and discuss his personal issues.

The final sequence reopens wounds and reverts back to the woman and her blind date at the café, focusing on the couple's singed body parts. The narrative evokes the horror of the café bombing that occurred at the beginning of the film, and reintegrates the unprocessed story at the end, as a shattered and dispersed image, as a fragment from the subconscious, of a nightmare whose bitterness stays with us long after we open our eyes.

Frozen Days spares us the viewing of the explosion, but not the sound or its implications for the character. The blast is again a sonic experience, which marks the detonation as a phantom.[27] As Distortion also does, Lerner's film utilizes aesthetics to create an effect of trauma, a "void," to convey a fractured story, which transforms the violent reality into a psychological thriller. The film is shot in black and white, except for the minutes prior to the explosion; only the use of chemicals brings out the vividness of life, and the explosion ends it. Like Bouzaglo, Lerner uses hard cuts between scenes and shots, twisted camera angles and contrasting shots - extreme close-ups vs. long shots. These techniques establish an unnatural perspective and the impression that the occurrences are the hallucinations of a drug addict, and not necessarily the flashbacks of a traumatized figure. They also contribute to a viewing experience that is characterized by disruption, constantly requiring reorientation and simultaneously undermining the viewers' certainty.

The story is told from a subjective perspective, through the eyes of the heroine. Her chat-room nickname is Meow, like the vocalization of a cat. It expresses some of her qualities, including her "multiple lives",

[27] R. Morag, Chronic Trauma..., p. 121. 
being a loner and her sneakiness. Likewise, it highlights her perpetually transforming character, as she steals a man's identity and is a criminal who sells drugs and becomes a terror-attack victim. Meow is captured mostly alone, in both the street and the apartment. Her interactions with people are indirect in most scenes, e.g. on the phone, on the intercom, in chat-rooms, or with Alex in total darkness. The only social interaction happens prior to the attack, in the nightclub, before the plot turns colourful and "real"; it ends as the viewer is thrown back to black and white with the explosion and the heroine seen on the floor. However, Meow is not a typical innocent victim of terror. She arrives in the club to sell drugs. Thus, she plays the role of a criminal, even a killer - a killer of minds, of consciousness, of identities - both her own, and those of her customers, all of whom wish to escape the burdens of reality. That is made even clearer when she chooses to adopt Alex's identity, also known as "0o8", (referring to oo, the code for "license to kill" in the James Bond novels and films), with whom she chats and whom she later finds out works as a security guard at a shopping mall.

Nevertheless, the inability of the main character to be aware of her own actions and conditions reflect how impossible it is to distinguish between reality and imagination. Thus, the disrupted images do not lead the viewer to conclusions, since it is not clear which images are just distressing dreams and which are reflecting Meow's subconscious as a result of the attack. Opposingly, the temporality of the film is that of repetition, of a circle or loop. As such, the narrative structure is referring to the temporality of trauma as a non-linear, repetitive structure of sudden recurrence.[28]

In Frozen Days, the heroine looks for someone that will give her "the time she needs." But, corresponding Langer's description of "durational time", [29] time has no meaning in the plot, and actions are frozen or in disarray. In contrast, memories and imagination have a dynamic of their own and support the blurry partitions not only between reality and imagination, but also between victim and perpetrator, man and woman, aggressor and protector. Thus, terrorism is not merely an act against innocent people, but also a part of a 'dialogue' on boundaries, responsibility and morality, which is embodied by the main figure.

Up to the last scene, the viewer has the impression that the entanglements around the drugs incite the plot and her hallucinations. The last scene re-frames the fantasy and the impression of power, as Meow is seen at the hospital, helpless, powerless, unconscious. Her screaming ends the fantasy of getting away from the terror scene in time, and thus being saved. In reality, she is severely wounded from the explosion, all alone and out of control.

In her dreams, Meow re-lives the past time and time again, as scenes repeat themselves so as to offer her numerous opportunities

[28] L. Langer, Memory's time: chronology and dura-

[29] Ibidem, p. 13. tion in Holocaust testimonies, [in:] L. Langer, Admitting the Holocaust: Collected Essays, Oxford 1995, p. 53-67. 
to do things differently, and possibly save herself and those around her. This alternative life could change her destiny from the sole result of an arbitrary act of terror to one guided by a rational chain of decision-making and actions. Meow says throughout the film that all she needs is time to start over again and love and be loved, but by the end of the film, it becomes apparent that time for her has frozen, leaving only her imagination fluid. She is trapped in-between the notions of 'not-yet' and 'not-anymore'.

The film 7 Minutes in Heaven was directed a few years after the end of the Intifada, in 2009, and it appears to be the right time to deal with and re-examine the events in retrospect. The film is a psychological drama that occurs a year after a terror attack. Galia, who was seven minutes clinically dead, suffers from post-traumatic amnesia and tries to trace the parts of the puzzle of her memory of that day. The film captures her post-traumatic state in everyday life, for example, her repulsion at seeing the flesh of the dead animal in the market, the fear of boarding a bus, and her panic attacks and delusions of seeing the people who were in the attack walking around her. When Galia shares her memories and says: "I remember," the screen turns black. We do not know if Galia is imagining with whom she is sharing her memories: with herself, or with Boaz the paramedic who saved her? Throughout the narrative, she reveals new details about her own life and about the event. However, the increasing uncertainty of her memory leaves the viewers deluded as well. As in other films discussed here, post-trauma is subject to an inner process of negotiation. While the institutions seem to stand in the way of getting the answers she needs, it is Galia's own courage and willingness to get her life back that helps her. Galia returns to the burned bus to just sit there. The sound of the explosion occurs a few minutes before the end of the film. Shots intersect memory and its reconstruction, merging images from the past and the present, until the point that Galia is falling unconscious, leaving the viewer behind with the horrific images of a burning bus and Galia, burned and covered with blood, in clinical death.

Screen memories of terrorism in Israeli war films
In-between the production years of The Bubble and 7 Minutes in Heaven, two popular Israeli movies reviewed episodes of a past military campaign, the Lebanon war. Both examples prove, as Raz Yosef has claimed, that recent Israeli films about this war are less interested in historical context than in personal and subjective perception as well as in the impact of memories that remain from wartime experiences. [30] The first of the two films, Beaufort, depicts an Israeli military unit guarding a strategic outpost in Lebanese territory, which is supposed be abandoned in context of the Israeli withdrawal from Southern Lebanon in 2000 . Focusing on the unit as a small and enclosed community, the

[30] R. Yosef, War fantasies: memory, trauma and ethics in Ari Folman's Waltz with Bashir, "Journal of Modern Jewish Studies” 2010, vol. 9, no. 3, pp. 314-15. 
film emphasizes social relations in contrast to military action. The war is present as a constant but diffused threat. In certain moments, violence disrupts the fragile social microstructure at the military enclave, thus introducing it as a shock to the soldiers, like a terrorist attack. In a similar way, the second movie, Waltz with Bashir, is characterized by such moments of suddenness and eruption that transform the wartime memories of the 1982 invasion of Lebanon into a substitute for the experiences of terrorist violence during the more recent Second Intifada. We encounter a paradoxical situation. On the one hand, current experiences of terrorist violence become invisible against memories of a military struggle; on the other hand, the re-encounter with the past war helps articulate personal experience of suicide terrorism, largely elided from Israeli popular culture. These films combine two conflicting subject-positions. On the one hand, they explore how the normality of war might turn young men into perpetrators, causing what Raya Morag has described as "perpetrator trauma".[31] On the other hand, they also demonstrate how everyone can become a victim, in a sudden eruption of violence. Correspondingly, both films are structured by a specific temporality that correlates to the temporality of terrorism and trauma. Characterized by duration on the one hand and rupture on the other, they oscillate between the notion of 'now-no-longer' and 'now-not-yet.'[32]

The Beaufort military base appears as a frozen time capsule. The progress of time, and thereby also the making of history, is disrupted. Instead, life at the base is characterized by routine, disconnected from the every-day life outside the military world. Correspondingly, Beaufort's temporal and spatial mode is one of displacement and repetition. It becomes "a twilight zone between reality and myth, past and present, life and death." [33] The visual style intensifies this encapsulated and displaced notion by emphasizing blocked sight and interrupted movements. These elements create a pattern that causes a sense of insecurity among the audience. Similarly, Waltz with Bashir presents its protagonist as being trapped in the past, encapsulated in a cycle of memories haunted by images of war and atrocities.[34]

These disruptive moments in both films can be interpreted as cinematic screen memories that interrelate wartime memories and military actions with experiences of terrorism. According to Freud, screen memories ('Deckerinnerungen') mask other memories; in many cases, earlier memories from childhood obscure more recent ones. [35] For Rothberg, screen memories are a source for the development of "multidirectional memory", a co-presence of different pasts that create

[31] R. Morag, Waltzing with Bashir: Perpetrator Trauma and Cinema, London 2013.

[32] Idem, Chronic Trauma..., p. 125.

[33] R. Yosef, Traces of War: Memory, Trauma, and the Archive in Joseph Cedar's Beaufort, "Cinema Journal" 2011, vol. 50, no. 2, p. 72.
[34] Idem, War Fantasies..., p. 314.

[35] L.A. Freeman, B. Nienass, L. Melamed, Screen Memory, "International Journal of Politics, Culture, and Society" 2013, pp. 1-2. 
an entangled network of layered memory frames. In his rereading of the concept of screen memories, Rothberg emphasizes the mode of "displacement" that "functions as much to open up lines of communication with the past as to close them off.' [36] Correspondingly, screen memories are not just a cover to obscure disturbing or troubling memories, but also a form of re-articulating them. Similarly, in the case of Israeli post-Second-Intifada war movies, war memories seem to indirectly reference and replace more recent but non-expressible experiences with suicide terrorism. According to Rothberg, "screen memory stands in or substituted a more disturbing or painful memory that it displaces from consciousness. [...] The mechanism of screen memory thus illustrates concretely how a kind of forgetting accompanies acts of remembrance, but this kind of forgetting is subject to recall.' [37]

Although Beaufort and Waltz with Bashir deal with aspects of recent Israeli history, they also serve as a sounding board for the still present memories of Second Intifada terrorism. However, they do not replace or mask these traumatic memories, but seek a way to address them, which creates a notion of synchrony of similar but different experiences. This results in multidirectional memories, "multidirectional not only because it stands at the centre of a potentially complex set of temporal relations, but also - and perhaps more importantly - because it both hides and reveals that which has been suppressed." [38]

The depiction of war as screen memory for the collective experience of terrorism works in these films due to the application of specific aesthetic techniques and patterns that originate less from the war film genre, and more from films about terrorism, or at least the intersection of both. Several scenes in Beaufort and Waltz with Bashir emphasize the suddenness of military attacks, explosions or ambush through an abrupt notion of suddenness that results from the contrast between every-day routine and the sudden outburst of violence. This notion of suddenness is, according to Morag, in this context "characterized by irreversibility, arbitrariness, and specific bi-temporality (caught between the already-occurred and the yet-to-occur.)"[39] An example is the first attack on the base in Beaufort. Following the enclosed shot of a soldier in an outpost the blast is foremost an acoustic experience that suddenly interrupts the soldiers' routine and is depicted from a distance briefly delayed in time. This corresponds to the common representations of terrorist attacks as described by Morag. The following shots depict the soldiers in enclosed and spatially displaced corridors, emphasizing the notion of duration and delay as well as the blocked sight, an aspect which is furthermore intensified through a screen of dust and smoke that clearly indicates the limits of visual experience and certainty. A corresponding scene in Waltz with Bashir shows Israeli

[36] M. Rothberg, Multidirectional Memory: Remembering the Holocaust in the Age of Decolonization, Stanford 2009, p. 12.
[37] Ibidem, p. 13.

[38] Ibidem, pp. 13-14.

[39] R. Morag, Chronic Trauma..., p. 125. 
soldiers walking through a peaceful forest. Piano music intensifies the calm and relaxed atmosphere, creating an irritating sense of security. The sounds of sudden movements disturb the scenery. We observe the shapes of armed children; however, our sight is blocked by trees. One child shoots an artillery shell, directly aiming towards the imaginary camera and the audience. The sonic space, however, is still dominated by the piano music. Then, the explosion disrupts the acoustic scene, followed by the abrupt ending of the background music when the film cuts to one of the former soldiers recalling this memory. The editing produces a narrative structure that reflects the sense of disruption.

In doing so, the films translate the Israeli experience of terrorist violence into the depiction of a war zone, an act that replaces the confrontation of terrorism as asymmetrical warfare with a master narrative derived from the context of classical military conflict. However, the multidirectional mode of these memories results in a contrary effect: the cinematic commemoration of past conflicts revisited in the framework of present experiences intensifies the social need to cope with the impact of terrorism and trauma in the present. In Beaufort, but even more so in the complex narrative structure of Waltz with Bashir, different elements intersect: perpetrator trauma, [40] traumatic memories from the Holocaust and indirect references to the traumatic effects of the Second Intifada terrorist attacks.

Personal traumatic memories may never be communicated, but they continue to affect one's ability to cope with events and influence their surroundings. As trauma theoreticians note, the traumatic memories of the protagonists are located in empty and broken spaces.[41] Nevertheless, the films underline the effects of trauma by embodying the damage that trauma causes to the self through the relationships of the traumatic person with others.

While these narratives contain clear examples of the kinds of events that evoke trauma, ranging from loss of a loved one to physical wound, it appears that all the films discussed here have re-conceptualised the notion of trauma. They did this as a collection of scattered fragments of an unnarrated memory that cannot engage its recollected components through typical stories, but rather must rely on an additional breakage. These include, for example, Haim's failing sexual relationship with his wife and the affair she has with another man, parallel to his writer's block and the theatre play in Distortion; Galia's relationship with her boyfriend, who did not survive the attack and dies, and her relationship with Boaz, the paramedic who saved her; the love affair between Noam and Ashraf, which eventually kills them both; the decision of Michal to leave her husband after losing her lover. In the process of transmission, the fragile components of trauma are very difficult to assemble, and thus fail to create a coherent story that can

Imagining terrorism: Conclusions 
produce what we call a personal narrated memory. Nevertheless, under such circumstances, the 'explosions' at the end of the films - silenced or not - add meaning to the traumatic memories by interrupting the instinctive internalisation of events in the mind of the viewer and thus providing a renewed meaning to the process and function of remembering. In a similar way, they resonate with other personal experiences of collective violence, such as war and military conflict, and thus turn into multidirectional memories in the sense of Rothberg. Migrated into the popular Israeli war film genre, implicit memories of the Second Intifada remain a potential subject for recollection.

By avoiding a complete depiction of an attack, combining sound and images from a terror scene, and instead using sound or changing frames, films extend the discourse on trauma and post-trauma, and transform it into an aesthetic reflection about the experience of violence. In this process, trauma is deconstructed both into and through human behaviour, making it comprehensible in the context of a specific cultural tradition. Coping with trauma resulting from a terrorist attack remains, however, a subjective matter of a socially problematic, complex reality. It integrates parallel, often competing, multidirectional elements, which not only affect but also question the cultural repertoire of commemoration and representation from a subjective - fragile - point of view. Although the word 'trauma' is not expressed in any of the films under discussion, the concept plays a persisting role and continues to shape the plots. As a subjective experience, the films express the post-traumatic suffering personified in mentally and emotionally isolated characters within a wounded collective environment and tradition that is powerless to help them. However, simultaneously, they seek for an experiential space beyond private mourning and the contested public sphere that acknowledges both the personal and the collective trauma of terrorism. Raymond Amsalem, Eldad Fribas, Nada Netz, EZ Films, KMH Film, Transfax Film Productions, 2008.

Avanim, Israel 2004. Dir. Raphaël Nadjari, Perf. Asi Levy, Uri Gavriel, Florence Bloch, Shaul Mizrahi, Danny Steg, BVNG Productions, Transfax Film Productions, 2.1 Films, CPB Films, Arte france, Centre National de la Cinématographie, Israeli Film Fund, Shilo Films, 2004.

Beaufort, Israel 2007. Dir. Joseph Cedar, Perf. Eli Eltonyo, Oshri Cohen, Ohad Knoller, Itay Tiran, Itay Turgeman, United King Films, Metro Communications, Movie Plus, The Yohoshua Rabinowits Foundation, Cinema Project, Keshet Broadcasting, Yes-DBD Satellite Services, CDI, Cinema Factory Production Ltd., Cinema Industry Association in Israel, 2007.

Distortion, Israel 2004. Dir. Haim Bouzaglo, Perf. Haim Bouzaglo, Smadar Kilchinsky, Avi Gilor, Amos Lavi, Haim Zanati, Tzufit Grant, Dor Zweigenboim, Mazel Productions, 2004

Frozen Days (Yamim Kfuim), Israel 2005. Dir. Danny Lerner, Perf. Anat Klausner, Sandra Sade, Uli Sternberg, Bleiberg Entertainment, DPI, 2005. 
The Bubble (Ha-Buah), Israel 2006. Dir. Eytan Fox, Pref. Ohad Knoller, Yousef Sweid, Daniella Wircer, Alon Friedman, Uchovsky Fox, Metro Productions, Ronen Ben-Tal Films, Feingold Productions, Israeli Film Fund, Keshet Hot, 2006.

To Be or Not to Be, USA 1942. Dir. Ernst Lubitsch, Perf. Carole Lombard, Jack Benny, Robert Stack, Romaine Film Corporation, United Artists, 1942.

Walk on Water, Israel 2004. Dir. Dir. Eytan Fox, Perf. Lior Ashkenazi, Knut Berger, Caroline Peters, Yousef Sweid, Lama Films, Israeli Film Fund, Hot, Fond Européen Media, 2004.

Waltz with Bashir (Vals im Bashir), Israel 2008. Dir. Ari Folman, Perf. Ari Folman, Ori Sivan, Mickey Leon, Ron Ben-Yishai, Yehezkel Lazarov, Zahava Solomon, Bridgit Folman Film Gang, Les Films d'Ici, Razor Film Produktion GmbH, Arte France, ITVS, Noga Communication, New Israeli Foundation for Cinema and Television, Medienboard Berlin-Brandenburg, Israeli Film Fund, Hot Telecommunication, YLE Teema, Télévision Suisse-Romande, Radio Télévision Belge Francophone, Special Broadcasting Service, 2008.

American Psychiatric Association, Diagnostic and Statistical Manual of Mental Disorders, 5th ed., Washington, DC, 2013, <https://www.psychiatry.org/patients-families/ptsd/what-is-ptsd> [accessed: July 12, 2017]

Baudrillard J., The Spirit of Terrorism and Requiem for the Twin Towers, trans. Ch. Turner, London-New York 2003

Boxer P., Sloan-Power E., Coping with violence: A comprehensive framework and implications for understanding resilience, "Trauma, Violence and Abuse" 2013, vol. 14 , no. 3

Cato D., Saving the Leader Within: The Impact of Childhood Trauma on Leadership, Bloomington 2011

Ellis J., Visible Fictions: Cinema, Television, Video, London-New York 1992

Elsaesser T., German Cinema - Terror and Trauma: Cultural Memory Since 1945, New York-London 2004

Elsaesser T., The trauma of terrorism: violence of the past in the present, "Trauma Interdisciplinar” 2015, vol. 6, no. 1, <http://editorarevistas.mackenzie.br/index. php/tint/article/viewFile/7947/5263> [accessed: May 21, 2018]

Freeman L.A., Nienass B., Melamed L., Screen memory, "International Journal of Politics, Culture, and Society" 2013, 26

International Dictionary of Psychoanalysis, ed. A. De Mijolla, London 2002

Jasinski L.J., Trauma and violence research, "Journal of Interpersonal Violence" 2005, pp. 412-417

Kansteiner W., Weilnböck H., Against the Concept of Cultural Trauma, Berlin 2008

Langer L., Memory's time: Chronology and duration in Holocaust testimonies, [in:] L. Langer, Admitting the Holocaust: Collected Essays, Oxford 1995

Lewis L., Kelly K., Allen J.G., Restoring Hope and Trust. An Illustrated Guide to Mastering Trauma, Baltimore 2004

Leys R., Trauma: A Genealogy, London-Chicago 1990

Morag R., Chronic trauma, the sound of terror, and current Israeli cinema, "Framework: The Journal of Cinema and Media" 2008, vol. 49, no. 1

Morag R., Interracial (Homo) sexualities: Post-Traumatic Palestinian and Israeli Cinema During the al-Aqsa Intifada (Diary of a Male Whore and The Bubble), "International Journal of Communication" 2010, vol. 4

Morag R., Waltzing with Bashir: Perpetrator Trauma and Cinema, London 2013

Nossek H., 'News media' - media events: Terrorist acts as media events, "European Journal of Communication Research" 2008, vol. 33, no. 3 
Pearlman L.A., Saakvitne K.W., Trauma and the Therapist: Countertransference and Vicarious Traumatization in Psychotherapy with Incest Survivors, New York 1995

Rothberg M., Multidirectional Memory: Remembering the Holocaust in the Age of Decolonization, Stanford 2009

Schauer M., Neuner F., Elbert T., Narrative Exposure Therapy: A Short-Term Intervention for Traumatic Stress Disorders after War, Terror, or Torture, Göttingen Cambridge 2005

The Horror of Trauma in Cinema: Violence Void Visualization, Newcastle upon Tyne, eds M. Elm, K. Kabalek, J.B. Köhne, Cambridge 2014

Yosef R., Traces of War: Memory, Trauma, and the Archive in Joseph Cedar's Beaufort, “Cinema Journal” 2011, vol. 50, no. 2

Yosef R., War fantasies: Memory, trauma and ethics in Ari Folman's Waltz with Bashir, "Journal of Modern Jewish Studies" 2010, vol. 9, no. 3 